\title{
ESTRATÉGIA DE COMERCIALIZAÇÃO EM MERCADOS DERIVATIVOS: CÁLCULO DE BASE E RISCO DE BASE DO BOI GORDO EM DIVERSAS LOCALIDADES DO BRASIL
}

\author{
Marketing strategy in derivatives markets: \\ calculation of risk and the basic foundation \\ of beef fat in various localities of Brazil
}

Envio 04.08.08 / Aceite 15.10.08

\author{
Vagner Rosalem ${ }^{1}$ \\ Cláudia Salgado Gomes ${ }^{2}$ \\ Maxwell Ferreira de Oliveira ${ }^{3}$
}

\begin{abstract}
Resumo
Com o presente trabalho, tem-se por objetivo avaliar os retornos que as estratégias de hedge com contratos futuros podem proporcionar aos produtores, exportadores e demais atores interessados em boi gordo, das regiões de São José do Rio Preto/Barretos, São Paulo; Noroeste do Paraná; Triângulo Mineiro; Goiânia, Goiás; e Cuiabá Mato Grosso, no período de setembro de 2000 a novembro de 2003. A pesquisa se justifica, pois a estratégia de se utilizar os mercados derivativos vem conquistando cada vez mais espaço, por causa de suas características, que possibilitam a adoção de hedge de preços. Os dados primários utilizados sobre o preço da arroba do boi gordo comercializada no mercado local foram coletados junto Centro de Estudos Avançados em Economia Aplicada (CEPEA - ESALQ/USP) e o preço da arroba do boi no mercado futuro foi levantando junto à Bolsa de Mercadorias \& Futuros (BM\&F). A diversidade dos valores da base e do risco de base encontrada demonstra que cada localidade apresenta características próprias de comercialização. No entanto, os vencimentos
\end{abstract}

\footnotetext{
${ }^{1}$ Professor Assistente do Departamento de Administração da Universidade Federal de Goiás (UFG). End.: Av. Dr. Lamartine Pinto de Avelar, 1120 - Setor Universitário - CEP: 75704-020 - Catalão - Goiás. E-mail: vagner@hotmail.com

${ }^{2}$ Mestre em Administração pela Universidade Federal de Lavras (UFLA). E-mail: claudiasgnep@yahoo.com.br ${ }^{3}$ Mestre em Administração pela UFLA. E-mail: maxwellarcos@yahoo.com.br
} 
que favorecem uma estratégia de hedge de venda são: abril, outubro e dezembro. Já os que favorecem uma estratégia de hedge de compra são: maio e julho.

Palavras-chave: Hedge; Contratos Futuros; Boi Gordo; Base; Risco de Base.

\begin{abstract}
This paper had as it's main objective to evaluate the feedback that cattlemen, exporters and other actors of the fed cattle market of São José do Rio Preto and Barrtos/SP; Northwester Paraná. Minas Gerais' triangle, Goiânia/GO and Cuiabá/MT; could obtain from future hedge strategies from September 2000 to November 2003. Such research is worth once it's new that derivative market has been increasingly adopted due to it's possibilities of use with hedge prices. The primary data about prices of fed cattle weight were obtained from the Applied Economy Advanced Studies' Center (CEPEA - ESALQ/USP) and future prices of fed cattle weight were obtained from Brazilian Mercantile \& Futures Exchange (BM\&FBovespa S.A.). It can be said, from the various values of basis and basis risk, that each of the regions has it's own commerce features. However, it was noticed that the more favorable months to hedge selling strategies were April, October and December, while May and July could be pointed as the best mouths to buying hedge strategies.
\end{abstract}

Keywords: Hedge; Futures Contracts; Beef Fat; Basic; Risk-Based.

\title{
1 Introdução
}

O setor agropecuário brasileiro é caracterizado por apresentar instabilidade de preços, produção e renda em níveis mais elevados que os demais. Nesse contexto, as condições de riscos e incertezas na atividade são acentuadas, cabendo ao produtor rural buscar alternativas para o gerenciamento desses riscos.

Entre as alternativas existentes, tem-se o mercado de derivativos, que é um instrumento eficiente e moderno de comercialização agrícola utilizado em larga escala nos países desenvolvidos. Trata-se de um mercado que surgiu a partir das formas tradicionais de comercialização com o objetivo de garantir preço no futuro.

No Brasil, os contratos derivativos agropecuários são negociados na Bolsa de Mercadorias \& Futuros (BM\&F), e, dentre as commodities que participam dessa negociação, está a do boi gordo.

Os negócios com boi gordo na BM\&F cresceram 98,50\% em 2004, o melhor desempenho entre os derivativos agropecuários negociados no ano, atingindo o total de 225.200 contratos. Mesmo com tal crescimento, o total de negócios na Bolsa representou, em 2004, 4,52 milhões de cabeças prontas para o abate, o equivalente a 18\% dos machos abatidos no ano ou $10 \%$ do total anual de abate de bovinos no Brasil.

Apesar desse expressivo percentual de crescimento, trata-se de um mercado muito pouco explorado, uma vez que o volume transacionado é muito baixo. A participação média desses contratos, em relação ao total negociado na BM\&F, é insignificante, estando em torno de $0,6 \%$.

Na visão de Fileni (1999), existem alguns aspectos para tal ocorrência. O primeiro deles está relacionado à falta de conhecimento operacional dos agentes envolvidos no processo produtivo, e o segundo se baseia na incerteza em relação ao comportamento dos preços entre o mercado à vista e o mercado futuro, que, por sua vez, é causada pela falta de liquidez. 
Autores como Barros et al. (2000), defendem que a liquidez é um dos principais fatores determinantes do êxito deste mercado, atrelando sua falta ao baixo número de contratos transacionados. Nesse sentido, os riscos dessas operações acabam se elevando e inibindo novas negociações, gerando um círculo vicioso.

A liquidez do mercado futuro afeta diretamente a diferença entre os preços à vista e futuro, sendo esta diferença definida como base (ROCHELLE, 1997). Em mercados com baixa liquidez, a volatilidade no preço futuro é maior, aumentando, assim, as dificuldades de sua avaliação. Nesse sentido, as operações estarão sujeitas a um maior risco de base, afetando o grau de efetividade do hedge.

A solidificação e a ampliação da condição brasileira de liderança mundial no mercado de carne bovina, em termos de volume exportado, correspondem à necessidade de ensejar esforço crescente para diferenciar seus produtos, a fim de incorporar maior valor agregado aos produtos e processos.

A continuidade da expansão das exportações de carne bovina brasileira vai exigir a melhoria de eficiência e profissionalização, não apenas da indústria exportadora como também de toda cadeia de produção de carne bovina. Nesse caso, os exportadores e os produtores mais tecnificados deverão utilizar, de forma crescente, as ferramentas financeiras do mercado futuro - como instrumento de proteção patrimonial e de suporte à procura de maior estabilidade de renda na atividade.

Nesse cenário, o mercado de derivativos agropecuários no Brasil possui um enorme campo para desenvolvimento, e o sucesso da estratégia de hedge dependerá principalmente do comportamento do diferencial entre o preço à vista e o preço futuro, ou seja, a "base".

Assim sendo, o objetivo principal deste trabalho é analisar o comportamento da base em cinco regiões criadoras de boi gordo no Brasil, com relação aos contratos futuros da BM\&F com diferentes vencimentos, a fim de dar maior subsídio à tomada de decisão dos hedgers desse mercado.

\section{Referencial teórico}

\subsection{Derivativos e origem histórica dos mercados futuros}

Os contratos futuros e de opções são exemplos do que se chama de derivativos ou produtos de derivativos, que podem ser definidos como instrumentos financeiros cujos preços dependem ou são "derivados" do preço de outras mercadorias (SIMON, 1994).

Vale notar que os derivativos não constituem propriamente uma inovação financeira, pois são instrumentos que acompanham a história da comercialização de bens há muito tempo, surgindo, em sua origem, como meios eminentemente facilitadores das trocas e comercialização.

A organização de mercados e feiras surgiu para satisfazer a demanda por determinados tipos de produtos e serviços. Esses lugares privilegiados tinham como objetivo facilitar as transações dos produtos físicos: as compras e vendas eram objetos de uma entrega imediata. Herdeiras dessas feiras e mercados, as primeiras bolsas de comércio vão aparecer na Europa no final do século XII (SIMON, 1994).

Elas se tornaram mais correntes no século XIX, quando o progresso dos transportes e o desenvolvimento industrial da Europa e da América do Norte provocaram uma forte expansão do comércio interno e internacional de commodities. Dentro dessas bolsas de comércio, as transações vão se tornando progressivamente mais complicadas. 
Os mercados futuros, formalmente tiveram origem no Japão feudal, onde teve início a troca de recibos de armazenagens de arroz estocado, no período compreendido entre o final do século XVII e início do século XVIII. Os comerciantes que aceitavam esses recibos de armazenagem de arroz em troca de mercadorias, na verdade, estavam efetuando um contrato para entrega futura, pois só iriam resgatar o arroz armazenado quando lhes fosse conveniente, no futuro. Esses recibos tornaram-se amplamente aceitáveis como moeda corrente, facilitando as transações.

Para Teixeira (1992), "derivativos" é a denominação genérica para um conjunto de instrumentos financeiros como os contratos a termo (forward contracts), futuros, opções e swaps "derivados" de vários produtos, tais como taxa de juros, câmbio, índices de mercado de ações, mercadorias e crédito. Eles são usados para diversos fins, que estão basicamente relacionados à administração de riscos, especulação financeira ou arbitragem.

Ainda segundo Teixeira (1992), assume-se que os contratos futuros negociados na Chicago Board of Trade (CBOT), que é hoje a maior bolsa de futuros do mundo, datam de meados da década de 1860, provavelmente 1865․ Com o rápido sucesso da CBOT, várias bolsas foram surgindo em toda a América do Norte, transformando os EUA na mais desenvolvida indústria de futuros do mundo. Além das bolsas de commodities americanas, há cerca de 50 outras ao redor do mundo. A maioria criada na década de 1980.

\subsection{Participantes do mercado futuro}

Segundo Silveira (2002), os participantes do mercado de derivativos financeiros incluem bancos, corretoras de títulos, tesourarias de empresas, formadores do mercado acionário, investidores institucionais, investidores privados, administradores de consórcios e distribuidores. Eles empregam os derivativos para três finalidades: fazer hedge, especular e fazer arbitragem:

- hedgers: os mercados futuros foram criados originalmente para atender às necessidades dos hedgers. Eles enfrentam o risco associado ao preço de um ativo e usam os mercados futuros e de opções para reduzi-lo ou eliminá-lo. Hedgear envolve tomar uma posição nos mercados futuros contrária à exposição que se tenha no mercado à vista. O hedge reduz a exposição ao risco de preços para quem tenha um perfil de risco oposto ou para investidores que desejem aceitá-lo em troca de uma oportunidade de lucro. Ao mesmo tempo em que o hedge com futuros elimina o risco de oscilação nos preços, ele impede a realização de lucros potencialmente maiores que possam advir de mudanças favoráveis. Além de tornar possível a transferência de risco, a prática de hedge também permite a proteção de margens de lucro, estabilizar fluxos de caixa, diversificar e melhorar a liquidez ou reduzir custos de transação;

- especuladores: enquanto os hedgers não desejam ficar expostos a movimentos adversos no preço de um ativo, os especuladores desejam apostar nas oscilações futuras de preço de uma ativo para ganhar dinheiro. O mercado futuro permite ao especulador obter uma alavancagem, pois, com um gasto inicial relativamente pequeno, será capaz de assumir uma grande posição especulativa. É um meio de aumentar a exposição ao risco, mas também de obter lucros potenciais;

- arbitradores: a arbitragem envolve travar um lucro sem risco, realizando transações simultâneas em dois ou mais mercados. É possível quando o preço futuro de um ativo perde a paridade com o preço à vista. Essa estratégia garante que os preços a futuro e à vista fiquem alinhados um com o outro. Assim, se qualquer um dos preços (futuro ou à vista) perder sintonia com o valor justo de mercado, a arbitragem fará com que volte à paridade. Normalmente, os 
arbitradores são grandes bancos que possuem uma fonte de financiamento barato ou grandes empresas que trabalham com o produto objeto do derivativo e que possuem a facilidade de negociá-lo no mercado à vista.

\subsection{A base e o risco de base}

Autores como Sharpe, Gordon e Bailey (1995), definem base como sendo a diferença de preços entre o mercado à vista e o seu correspondente no mercado futuro. É possível verificar que o preço à vista pode ser superior (inferior) ao seu correspondente preço futuro; dessa forma, a base será positiva (negativa).

Caso o preço à vista tenha um preço maior do que o preço futuro (ou o futuro apresente uma queda maior do que o preço à vista), ocorre o fortalecimento da base, beneficiando os agentes que estão vendidos em contratos futuros. Contudo, quando o preço futuro tiver um crescimento maior do que o do preço à vista, a base diminui, isto é, sofre um enfraquecimento (SHARPE, GORDON e BAILEY, 1995).

Ainda segundo Sharpe, Gordon e Bailey (1995), normalmente observa-se que os preços à vista e futuro se movem na mesma direção, porém, este movimento, além de não ser simultâneo, não acontece com a mesma intensidade. É possível, assim, existirem movimentos imprevisíveis em relação à base, que são definidos como risco de base. Dessa forma, fica claro o motivo pelo qual o mercado futuro não elimina totalmente o risco relativo aos preços, e sim o reduz.

Na concepção de Barros e Aguiar (2005), o sucesso da estratégia de hedge dependerá do comportamento conjunto dos preços à vista e futuro, ou seja, dependerá do comportamento diferencial entre o preço à vista e o preço futuro, denominado base. O conhecimento dos valores e dos padrões de comportamento da base é muito valioso em qualquer decisão que envolva o uso de mercados de futuros como uma ferramenta de administração do risco do preço.

Assim, o hedger precisa conhecer o padrão de comportamento dos preços à vista e futuro, nos vários períodos do ano e nas principais regiões criadoras, a fim de estabelecer uma estratégia de hedge seletivo em que, além de reduzir seu risco de preço, possa obter lucro.

O conhecimento do comportamento da base permite escolher os contratos e os momentos de entrada e saída do mercado para que haja maiores chances de que o ganho obtido em um mercado supere a perda ocorrida em outro. Esse conhecimento também é fundamental quando se pretende estabelecer estratégias de hedgers que utilizam os contratos de opções, pois, ao exercer a opção, o hedger tomará uma posição em relação a um contrato futuro, que poderá ser de vendida ou comprada.

Para Castro Júnior (1999), o risco de hedge está associado ao risco da base que pode ser quantificado por meio da variância ou desvio padrão durante o período de vigência do contrato. Os fatores que determinam o risco de base são definidos como sendo: tipo e qualidade do produto, localização do mercado e tempo de vigência do contrato. Relacionado ao primeiro, tem-se que o tipo e a qualidade da mercadoria no mercado físico (local) podem diferir das especificações do contrato futuro, acrescentando um elemento de incerteza e contribuindo para o aumento do risco de base. O risco de base é definido por meio do desvio padrão das bases. 


\section{Metodologia}

\subsection{Modelo analítico}

Adotando-se a definição de base de Sharpe, Alexander e Bailey (1995), como sendo o preço à vista menos o preço futuro, deduz-se a seguinte equação:

$\mathrm{Bt},(t+n), i=\mathrm{Pt}, i-\mathrm{Ft},(t+n)$,

(Equação 1)

em que:

- Bt, $(t+n), i=$ base no momento $t$, em relação ao contrato com vencimento em $(t+n)$

para a localidade $i$;

- Pt, $i=$ preço à vista em $t$, na localidade $i$;

$-F t,(t+n)=$ preço do contrato futuro com vencimento em $(t+n)$, no momento $t$.

O risco de base foi quantificado pela variância, ou seja:

$R_{b}=\frac{\sum(X i-\bar{X})^{2}}{n-1}$

(Equação 2)

em que:

$-\mathrm{R}_{\mathrm{b}}=$ risco de base;

$-\bar{X}_{\mathrm{i}}=$ observação;

$-\mathrm{X}=$ média das observações;

$-\mathrm{n}=$ número de observações.

\subsection{Procedimentos e fontes de dados}

Analisou-se o comportamento das bases, por meio dos procedimentos descritos a seguir.

As séries diárias, utilizadas no presente trabalho, referem-se ao preço da arroba de boi gordo, das regiões de São José do Rio Preto/Barretos (estado de São Paulo), Noroeste do Paraná, Triângulo Mineiro, Goiânia (estado de Goiás) e Cuiabá (estado do Mato Grosso), no período de setembro de 2000 a novembro de 2003, e foram obtidos junto ao Centro de Estudos Avançados em Economia Aplicada (CEPEA - ESALQ/USP). As séries diárias da Bolsa de Mercadorias \& Futuros (BM\&F), relativas aos contratos futuros de boi negociados nessa Bolsa, no período de setembro de 2000 a novembro de 2003, foram obtidas por meio do banco de dados da BM\&F.

Em razão dos feriados ou simplesmente da ausência de cotação, as datas das observações de preços que não foram coincidentes foram eliminadas das séries para sua homogeneização e operacionalização. Assim, as séries diárias das regiões supracitadas e dos contratos futuros foram padronizadas, mantendo-se somente os dias comuns a todas as séries.

A base diária foi calculada por meio da equação 1, para as cinco regiões, em relação ao contrato futuro de boi da BM\&F, com vencimento nos meses de abril, maio, julho, agosto, outubro e dezembro, dos anos de 2000, 2001 e 2003. As bases diárias encontradas foram transformadas em bases mensais, através de médias, para melhor visualização dos resultados. 
Foi analisado o comportamento mensal da base no período de sete meses que antecedem cada vencimento, excluindo o mês do vencimento. Tal exclusão foi feita para eliminar a possibilidade de squeezes nesse período, situação em que o investidor, com posição vendida ou comprada no mercado futuro, não consegue inverter sua posição e sair desse mercado ou adquirir a commodity no mercado à vista para entregar, no caso de estar com posição vendida, exceto por um preço substancial maior ou menor que o valor relativo desse contrato ou dessa commodity.

O comportamento mensal da base e o risco de base, para cada vencimento do contrato futuro e para cada região, são analisados a partir de médias de três anos, de 2001 a 2003.

Finalmente, pela variação da base para cada região, em relação a cada vencimento do contrato futuro, é possível identificar períodos de fortalecimento e de enfraquecimento da base e quantificar essas variações.

\section{Análise e discussão dos resultados}

Os resultados estão apresentados por vencimento do contrato futuro de boi, possibilitando, dessa forma, a comparação entre as regiões estudadas. Em seguida, fez-se uma análise conjunta do comportamento da base e do risco de base nos diversos vencimentos e nas cinco regiões.

\subsection{Comportamento da base para cada vencimento}

- Contrato futuro de boi com vencimento em abril

O período analisado do comportamento da base do contrato futuro de boi com vencimento em abril é de setembro do ano anterior a março do ano do vencimento. A Figura 1 demonstra o comportamento da base para esse vencimento do contrato futuro de boi nas cinco regiões estudadas.

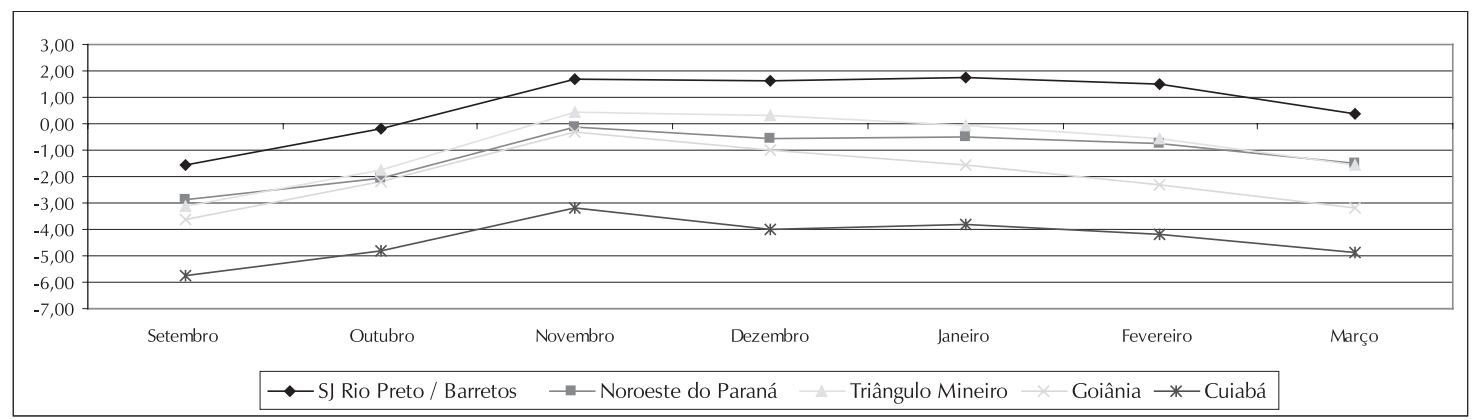

Fonte: Resultado da pesquisa.

Figura 1 - Comportamento mensal da base ( $\$$ \$arroba) em relação ao contrato futuro de boi com vencimento em abril, média de três anos (2001 a 2003).

Constata-se que, pela análise da Tabela 1, que entre setembro e outubro, há um fortalecimento da base em todas as regiões, assim como entre outubro e novembro. Observa-se um enfraquecimento da base entre novembro e dezembro para a maioria das regiões, sendo que, no Triângulo Mineiro e em São José do Rio Preto/Barretos, a base se manteve constante. Há um pequeno fortalecimento da base entre dezembro e janeiro nas regiões de São José do Rio Preto/Barretos e Cuiabá, um enfraquecimento no Triângulo Mineiro e Goiânia, e, no 
Noroeste do Paraná, a base se manteve constante. Há também um pequeno enfraquecimento da base, entre janeiro e fevereiro, em todas as regiões, e essa situação se estende até março.

Tabela 1 - Variações mensais da base (R $\$$ /arroba) em relação ao contrato futuro de boi com vencimento em abril, média de três anos (2001 a 2003) e o risco de base

\begin{tabular}{c|c|c|c|c|c}
\hline Meses/Regióes & $\begin{array}{c}\text { SJ Rio } \\
\text { Preto/ } \\
\text { Barretos }\end{array}$ & $\begin{array}{c}\text { Noroeste do } \\
\text { Paraná }\end{array}$ & $\begin{array}{c}\text { Triângulo } \\
\text { Mineiro }\end{array}$ & Goiânia & Cuiabá \\
\hline setembro/outubro & 1,37 & 0,84 & 1,39 & 1,46 & 0,93 \\
\hline outubro/novembro & 1,9 & 1,9 & 2,21 & 1,85 & 1,6 \\
\hline novembro/dezembro & $-0,07$ & $-0,39$ & $-0,11$ & $-0,7$ & $-0,78$ \\
\hline dezembro/janeiro & 0,11 & 0,04 & $-0,37$ & $-0,56$ & 0,18 \\
\hline janeiro/fevereiro & $-0,24$ & $-0,25$ & $-0,55$ & $-0,73$ & $-0,36$ \\
\hline fevereiro/março & 1,11 & $-0,75$ & 1 & $-0,84$ & $-0,7$ \\
\hline Fortalecimento & 4,18 & 1,39 & 3,57 & 0,48 & 0,87 \\
Risco de base & 1,60 & 0,98 & 1,74 & 1,34 & 0,69 \\
\hline
\end{tabular}

Fonte: Resultado da pesquisa.

Analisando o comportamento da base de setembro a março, constatou-se que houve um fortalecimento, sendo que este diferiu entre as regiões estudadas. Por exemplo, São José do Rio Preto/Barretos apresentou o maior fortalecimento, seguido pela região do Triângulo Mineiro, em relação às demais regiões. Assim sendo, essas duas regiões possibilitariam uma estratégia de hedge de venda, em que haveria uma possibilidade de ganho. Entretanto, essas duas regiões têm os maiores riscos de base entre as cinco analisadas, mas esse risco não é suficiente para comprometer a estratégia.

- Contrato futuro de boi com vencimento em maio

O período analisado do comportamento da base do contrato futuro de boi com vencimento em maio se estende de outubro do ano anterior a abril do ano do vencimento. A Figura 2 mostra o comportamento da base para esse vencimento do contrato futuro de boi nas cinco regiões estudadas.

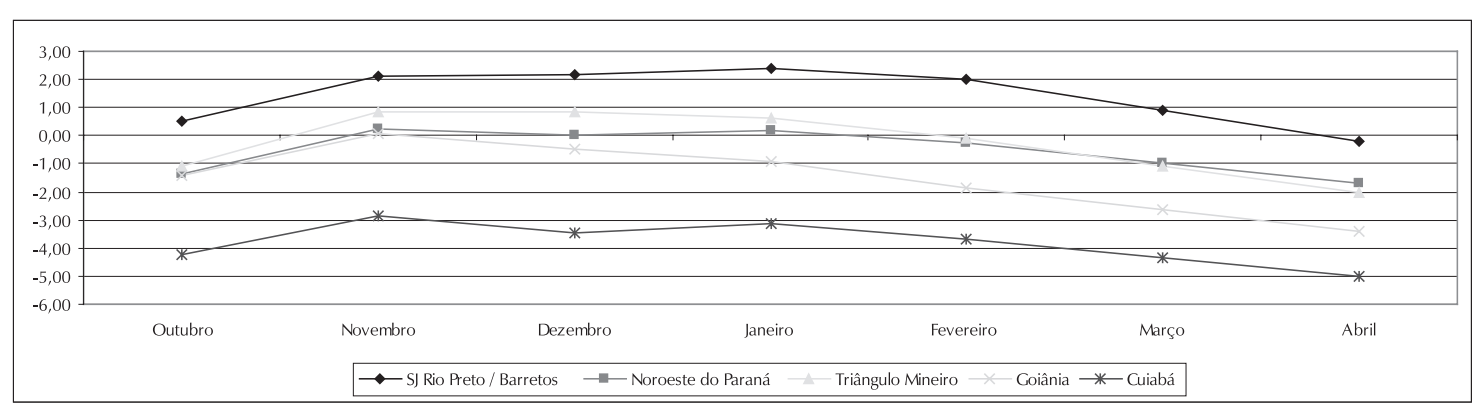

Fonte: Resultado da pesquisa.

Figura 2 - Comportamento mensal da base (R\$arroba) em relação ao contrato futuro de boi com vencimento em maio, média de três anos (2001 a 2003).

Observa-se um fortalecimento da base de outubro a novembro em todas as regiões. De novembro a dezembro, nota-se um pequeno fortalecimento em São José do Rio Preto/ 
Barretos e no Triângulo Mineiro, apresentando um leve enfraquecimento da base no Noroeste do Paraná, e um enfraquecimento um pouco maior nas outras regiões.

De dezembro a janeiro há um pequeno fortalecimento da base em SJ Rio Preto/ Barretos, Noroeste do Paraná e Cuiabá, havendo um enfraquecimento da base de janeiro para fevereiro em todas as regiões, situação essa que se estende até o mês de abril (Tabela 2).

Tabela 2 - Variações mensais da base (R $\$$ /arroba) em relação ao contrato futuro de boi com vencimento em maio, média de três anos (2001 a 2003) e o risco de base

\begin{tabular}{c|c|c|c|c|c}
\hline Meses/Regiões & $\begin{array}{c}\text { SJ Rio } \\
\text { Preto/ } \\
\text { Barretos }\end{array}$ & $\begin{array}{c}\text { Noroeste do } \\
\text { Paraná }\end{array}$ & $\begin{array}{c}\text { Triângulo } \\
\text { Mineiro }\end{array}$ & Goiânia & Cuiabá \\
\hline outubro/novembro & 1,57 & 1,61 & 1,93 & 1,49 & 1,42 \\
\hline novembro/dezembro & 0,08 & $-0,23$ & 0,04 & $-0,53$ & $-0,62$ \\
\hline dezembro/janeiro & 0,24 & 0,16 & $-0,25$ & $-0,45$ & 0,32 \\
\hline janeiro/fevereiro & $-0,42$ & $-0,43$ & $-0,72$ & $-0,9$ & $-0,55$ \\
\hline fevereiro/março & $-1,1$ & $-0,74$ & $-0,99$ & $-0,83$ & $-0,69$ \\
\hline março/abril & 1,12 & 0,71 & 0,95 & 0,72 & 0,64 \\
\hline Fortalecimento & 1,49 & 1,08 & 0,96 & $-0,5$ & 0,52 \\
Risco de base & 1,01 & 0,62 & 1,30 & 1,46 & 0,58 \\
\hline
\end{tabular}

Fonte: Resultado da pesquisa.

Com relação ao comportamento da base, de outubro a abril, constatou-se que houve um enfraquecimento em todas as regiões analisadas, sendo que este diferiu entre as regiões. As regiões que apresentaram um maior enfraquecimento da base foram a região de Goiânia, seguida pela região de Cuiabá. Dessa forma, principalmente essas duas regiões possibilitariam uma estratégia de hedge de compra, em que haveria uma possibilidade de ganho. Todas as regiões apresentam um alto risco de base se comparado com o comportamento da base. Dessa forma, a região que apresenta o maior risco de base é a de Goiânia, seguida pelo Triângulo Mineiro. Esse elevado risco de base poderia comprometer as estratégias de hedge.

- Contrato futuro de boi com vencimento em julho

O período de análise para o contrato futuro de boi com vencimento em julho é de dezembro do ano anterior a junho do ano do vencimento. A maioria das regiões apresenta um mesmo comportamento da base ao longo desse período, como mostra a Figura 3. 


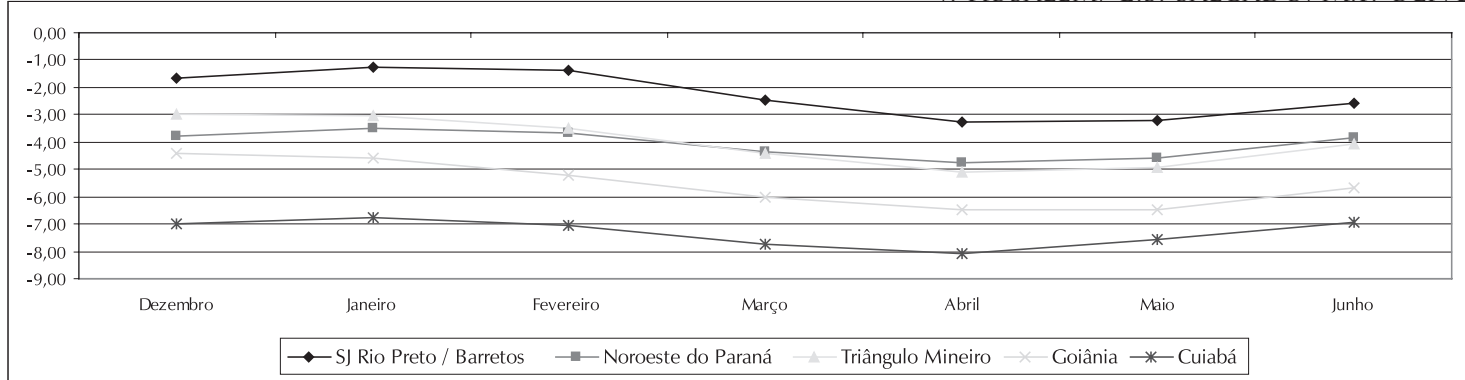

Fonte: Resultado da pesquisa.

Figura 3 - Comportamento mensal da base ( $\mathrm{R} \$$ /arroba) em relação ao contrato futuro de boi com vencimento em julho, média de três anos (2001 a 2003).

Observa-se um fortalecimento da base, de dezembro a janeiro, em São José do Rio Preto/Barretos, Noroeste do Paraná e, de maneira mais leve, em Cuiabá, e um pequeno enfraquecimento da base em Goiânia, e, principalmente, no Triângulo Mineiro. De janeiro a fevereiro, há um pequeno enfraquecimento em todas as regiões, situação essa que se estende até abril. De abril a maio, a base se mantém praticamente constante em Goiânia, em relação ao período anterior, mas, nas demais regiões, há um fortalecimento da base, que é mantido até junho em todas as regiões (Tabela 3).

Tabela 3 - Variações mensais da base ( $\mathrm{R}$ /arroba) em relação ao contrato futuro de boi com vencimento em julho, média de três anos (2001 a 2003) e o risco de base

\begin{tabular}{c|c|c|c|c|c}
\cline { 2 - 5 } Meses/Regióes & $\begin{array}{c}\text { SJ Rio } \\
\text { Preto/ } \\
\text { Barretos }\end{array}$ & $\begin{array}{c}\text { Noroeste do } \\
\text { Paraná }\end{array}$ & $\begin{array}{c}\text { Triângulo } \\
\text { Mineiro }\end{array}$ & Goiânia & Cuiabá \\
\cline { 2 - 6 } dezembro/janeiro & 0,42 & 0,27 & $-0,03$ & $-0,16$ & 0,22 \\
\hline janeiro/fevereiro & $-0,15$ & $-0,15$ & $-0,46$ & $-0,63$ & $-0,27$ \\
\hline fevereiro/março & $-1,06$ & $-0,71$ & $-0,95$ & $-0,79$ & $-0,66$ \\
\hline março/abril & $-0,84$ & $-0,43$ & $-0,68$ & $-0,45$ & $-0,36$ \\
\hline abril/maio & 0,06 & 0,19 & 0,2 & $-0,01$ & 0,51 \\
\hline maio/junho & 0,67 & 0,77 & 0,86 & 0,78 & 0,62 \\
\hline Fortalecimento & $-0,9$ & $-0,06$ & $-1,06$ & $-1,26$ & 0,06 \\
Risco de base & 0,71 & 0,26 & 0,75 & 0,70 & 0,23 \\
\hline
\end{tabular}

Fonte: Resultado da pesquisa.

Analisando o comportamento da base de dezembro a junho, percebe-se que houve um fortalecimento em algumas regiões e o enfraquecimento em outras. As regiões de São José do Rio Preto/Barretos, Triângulo Mineiro e Goiânia tiveram um fortalecimento, o que possibilitaria uma estratégia de hedge de venda, em que haveria uma possibilidade de ganho. Já na região do Noroeste do Paraná e Cuiabá, houve um enfraquecimento da base, o que justificaria uma estratégia de hedge diferente, ou seja, de compra. O risco de base pode ser considerado expressivo para todas as regiões analisadas se comparado com o comportamento da base. As regiões que apresentaram maior risco de base foram: Triângulo Mineiro, Goiânia e São José do Rio Preto/Barretos, respectivamente. Isso significa que os hedgers têm de estar atentos a esse risco, que pode comprometer as suas estratégias.

- Contrato futuro de boi com vencimento em outubro

O período de análise para o contrato futuro de boi com vencimento em outubro é de março do ano anterior a setembro do ano do vencimento. Todas as regiões apresentaram um comportamento semelhante da base ao longo desse período, como mostra a Figura 4. 


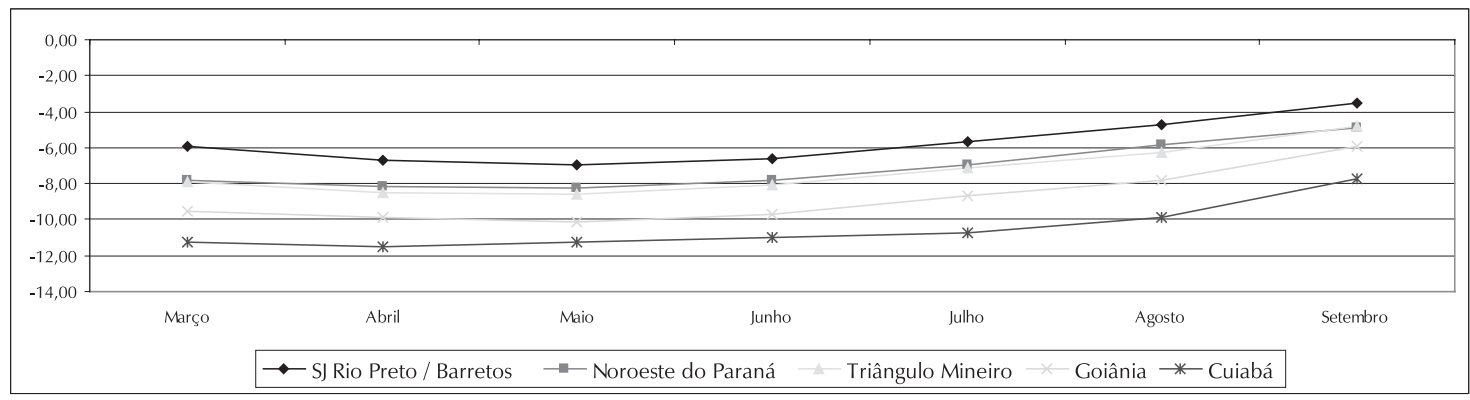

Fonte: Resultado da pesquisa.

Figura 4 - Comportamento mensal da base ( $\mathrm{R} \$$ /arroba) em relação ao contrato futuro de boi com vencimento em outubro, média de três anos (2001 a 2003).

Observa-se um enfraquecimento da base de março para abril em todas as regiões, acontecendo o mesmo de abril a maio, com exceção de Cuiabá. Nos demais meses, de maio a setembro, há um fortalecimento da base em todas as regiões (Tabela 4).

Tabela 4 - Variações mensais da base (R \$arroba) em relação ao contrato futuro de boi com vencimento em outubro, média de três anos (2001 a 2003) e o risco de base.

\begin{tabular}{c|c|c|c|c|c}
\cline { 2 - 6 } Meses/Regióes & $\begin{array}{c}\text { SJ Rio } \\
\text { Preto/ } \\
\text { Barretos }\end{array}$ & $\begin{array}{c}\text { Noroeste do } \\
\text { Paraná }\end{array}$ & $\begin{array}{c}\text { Triângulo } \\
\text { Mineiro }\end{array}$ & Goiânia & Cuiabá \\
\cline { 2 - 6 } março/abril & $-0,73$ & $-0,32$ & $-0,58$ & $-0,34$ & $-0,25$ \\
\hline abril/maio & $-0,23$ & $-0,1$ & $-0,1$ & $-0,3$ & 0,22 \\
\hline maio/junho & 0,34 & 0,44 & 0,54 & 0,45 & 0,29 \\
\hline junho/julho & 0,87 & 0,88 & 0,94 & 1,06 & 0,27 \\
\hline julho/agosto & 0,96 & 1,09 & 0,9 & 0,81 & 0,79 \\
\hline agosto/setembro & 1,25 & 1,02 & 1,4 & 1,95 & 2,18 \\
\hline Fortalecimento & 2,46 & 3,01 & 3,10 & 3,63 & 3,50 \\
Risco de base & 1,50 & 1,71 & 1,90 & 2,29 & 1,73 \\
\hline
\end{tabular}

Fonte: Resultado da pesquisa.

Com relação ao comportamento da base de março a setembro, constatou-se que houve um fortalecimento em todas as regiões analisadas, sendo que este diferiu entre as regiões. As regiões que apresentaram um maior fortalecimento da base foram Goiânia, seguida pela região de Cuiabá. Dessa forma, principalmente estas duas regiões possibilitariam uma estratégia de hedge de venda, em que haveria uma possibilidade de ganho. As regiões apresentam um risco de base expressivo, se comparado com o comportamento da base, principalmente a região de Goiânia. Dessa forma, esse risco de base expressivo poderia comprometer as estratégias de hedge.

- Contrato futuro de boi com vencimento em dezembro

O período de análise para o contrato futuro de boi com vencimento em dezembro é de maio a novembro do ano do vencimento. A Figura 5 mostra o comportamento da base nas cinco regiões estudadas. 


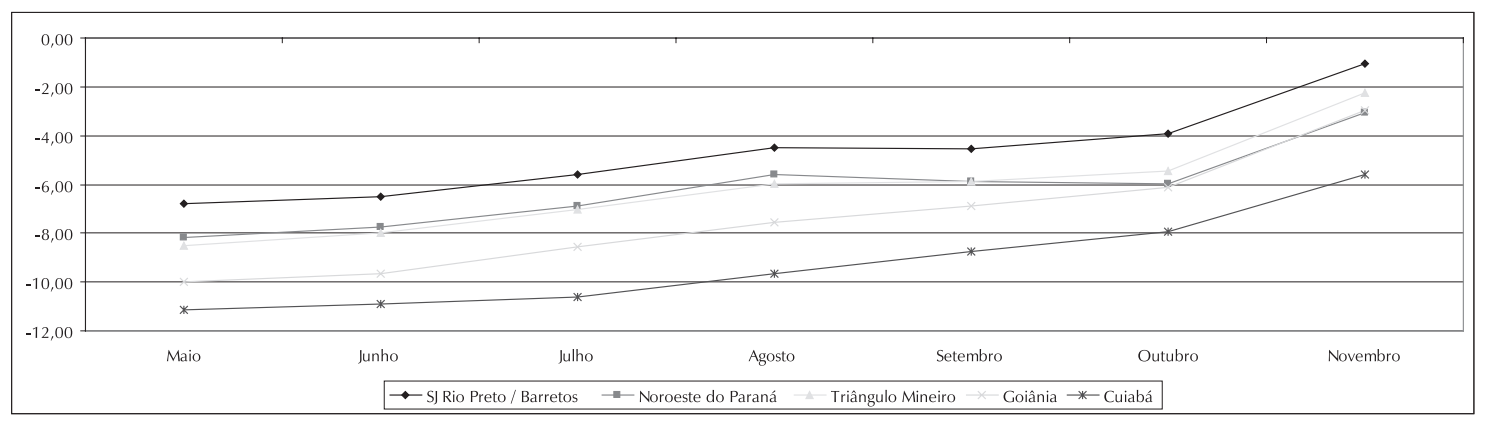

Fonte: Resultado da pesquisa.

Figura 5 - Comportamento mensal da base ( $\mathrm{R} \$$ /arroba) em relação ao contrato futuro de boi com vencimento em novembro, média de três anos (2001 a 2003).

Observa-se um fortalecimento da base, em todas as regiões, de maio a agosto. De agosto a setembro, há um fortalecimento da base em Goiânia e Cuiabá e, de maneira mais leve, no Triângulo Mineiro. Há um leve enfraquecimento da base no Noroeste do Paraná, de setembro a outubro, e um pequeno fortalecimento nas demais regiões. Este fortalecimento é observado em todas as regiões, de outubro a novembro, de maneira mais efetiva.

Tabela 5 - Variações mensais da base (R\$/arroba) em relação ao contrato futuro de boi com vencimento em dezembro, média de três anos (2001 a 2003) e o risco de base.

\begin{tabular}{c|c|c|c|c|c}
\cline { 2 - 6 } Meses/Regióes & $\begin{array}{c}\text { SJ Rio } \\
\text { Preto/ } \\
\text { Barretos }\end{array}$ & $\begin{array}{c}\text { Noroeste do } \\
\text { Paraná }\end{array}$ & $\begin{array}{c}\text { Triângulo } \\
\text { Mineiro }\end{array}$ & Goiânia & Cuiabá \\
\cline { 2 - 6 } maio/junho & 0,3 & 0,41 & 0,49 & 0,37 & 0,24 \\
\hline junho/julho & 0,89 & 0,9 & 0,96 & 1,07 & 0,29 \\
\hline julho/agosto & 1,14 & 1,26 & 1,08 & 0,99 & 0,97 \\
\hline agosto/setembro & $-0,04$ & $-0,26$ & 0,11 & 0,66 & 0,89 \\
\hline setembro/outubro & 0,6 & $-0,11$ & 0,43 & 0,77 & 0,81 \\
\hline outubro/novembro & 2,84 & 2,93 & 3,17 & 3,17 & 2,35 \\
\hline $\begin{array}{c}\text { Fortalecimento } \\
\text { Risco de base }\end{array}$ & 5,73 & 5,13 & 6,24 & 7,03 & 5,55 \\
\cline { 2 - 6 } & 3,73 & 2,87 & 4,26 & 5,76 & 3,95 \\
\hline
\end{tabular}

Fonte: Resultado da pesquisa.

Analisando o comportamento da base de maio a novembro, percebeu-se que houve um expressivo fortalecimento em todas as regiões analisadas. As regiões que apresentaram um maior fortalecimento da base foram a de Goiânia, seguida pela região do Triângulo Mineiro. Dessa forma, principalmente estas duas regiões possibilitariam uma estratégia de hedge de venda, em que haveria uma possibilidade de ganho. Entretanto, todas as regiões apresentam um alto risco de base, se comparado com o comportamento da base. Nesse sentido, a região que apresenta o maior risco de base é o Triângulo Mineiro, seguida por Goiânia. Esse elevado risco de base poderia comprometer as estratégias de hedge. 


\subsection{Análise conjunta do comportamento da base e do risco de base do contrato futuro do boi nos diversos vencimentos e nas cinco regiões}

Analisando o período de sete meses de comercialização do contrato de boi para os vencimentos de abril, maio, julho, outubro e dezembro, tem-se que o contrato de dezembro apresenta os maiores fortalecimentos, principalmente em Goiânia, que também apresentou o menor fortalecimento com o contrato com vencimento em julho, mês em que ocorreram os menores fortalecimentos, conforme mostra a Figura 6.

O contrato com vencimento em abril apresentou maior fortalecimento em São José do Rio Preto/Barretos e menor fortalecimento em Goiânia, havendo uma diferença de R\$ 3,7/a. entre essas regiões. A região de São José do Rio Preto/Barretos também apresentou maior fortalecimento para o contrato futuro com vencimento em maio, enquanto o menor fortalecimento para este contrato aconteceu em Goiânia, com uma diferença de R\$1,99/a. entre essas regiões. Para o contrato com vencimento em julho, o maior fortalecimento ocorreu na região de Cuiabá, e o menor em Goiânia, sendo de R\$1,32/a. a variação entre elas. Goiânia, porém, obteve um maior fortalecimento para o contrato futuro com vencimento em outubro, enquanto, para este contrato, o menor fortalecimento ocorreu em São José do Rio Preto/ Barretos, sendo a diferença entre essas regiões de $R \$ 1,17 / a$. Para o contrato com vencimento em dezembro, o maior fortalecimento aconteceu em Goiânia, e o menor no Noroeste do Paraná, sendo a diferença de $\mathrm{R} \$$ 1,9/a. entre essas regiões. Interessante notar que o Triangulo Mineiro e o Noroeste do Paraná não se apresentaram com destaque, nem com maior fortalecimento e nem com menor fortalecimento, em nenhum dos vencimentos.

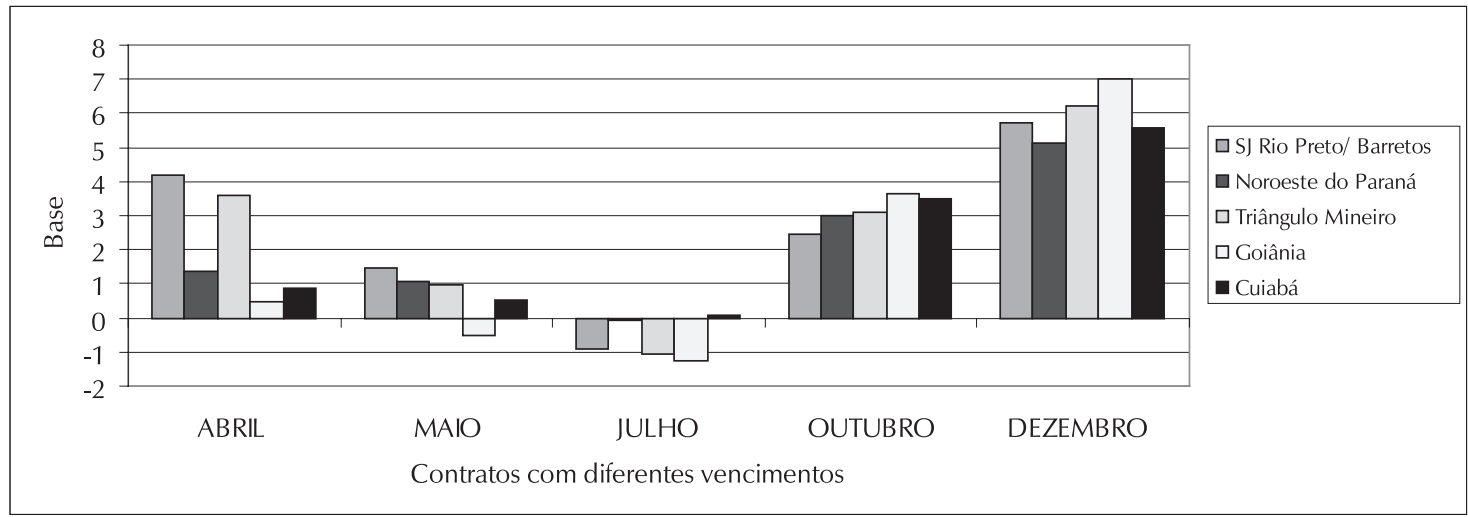

Figura 6 - Variação da base (R\$/arroba) no período de sete meses, em cada região e para diversos vencimentos do contrato futuro de boi.

A Tabela 6 resume o risco de base para cada região em relação aos vencimentos do contrato futuro de boi. 
Tabela 6 - Risco de base para as regiões analisadas em relação aos vencimentos do contrato futuro de boi

\begin{tabular}{|c|c|c|c|c|c}
\cline { 2 - 6 } Vencimento/Região & $\begin{array}{c}\text { SJ Rio } \\
\text { Preto/ } \\
\text { Barretos }\end{array}$ & $\begin{array}{c}\text { Noroeste do } \\
\text { Paraná }\end{array}$ & $\begin{array}{c}\text { Triângulo } \\
\text { Mineiro }\end{array}$ & Goiânia & Cuiabá \\
\cline { 2 - 6 } abril & 1,60 & 0,98 & 1,74 & 1,34 & 0,69 \\
\hline maio & 1,01 & 0,62 & 1,30 & 1,46 & 0,58 \\
\hline julho & 0,71 & 0,26 & 0,75 & 0,70 & 0,23 \\
\hline outubro & 1,50 & 1,71 & 1,90 & 2,29 & 1,73 \\
\hline dezembro & 3,73 & 2,87 & 4,26 & 5,76 & 3,95 \\
\hline
\end{tabular}

Fonte: Resultado da pesquisa.

O contrato com vencimento em dezembro apresentou os maiores riscos de base devido ao fato de se terem maiores riscos nos meses de início de "safra", já que a incerteza é maior devido à entrada de "nova safra", sendo que os contratos com vencimento em julho apresentaram os menores riscos de base.

Em relação a cada vencimento do contrato, tem-se que o contrato com vencimento em abril apresentou um maior risco de base no Triângulo Mineiro e um menor risco de base em Cuiabá, que também apresentou o menor risco de base para contratos com vencimento em maio e julho. Goiânia obteve um maior risco de base para os contratos com vencimento em maio e dezembro.

É interessante notar, comparando-se os dados da Figura 6 e da Tabela 6, que nem sempre as regiões que apresentaram os maiores ou menores fortalecimentos, apresentaram também os maiores ou menores riscos de base, respectivamente.

\section{Conclusão}

O comportamento da base para os vencimentos nos meses de abril, maio, julho, outubro e dezembro, dos anos de 2000, 2001 e 2003 é semelhante em São José do Rio Preto/Barretos (estado de São Paulo), Noroeste do Paraná, Triângulo Mineiro, Goiânia (estado de Goiás) e Cuiabá (estado do Mato Grosso), conforme pode ser observado nas figuras. Isso significa que a base apresentou o mesmo comportamento em todas as regiões analisadas, ou seja, nos meses em que houve um fortalecimento da base em uma região, ele também ocorreu em outra e vice-versa.

Os melhores momentos encontrados para a utilização de uma estratégia de hedge de venda são: de setembro do ano anterior a março do ano do vencimento, utilizando o contrato futuro com vencimento em abril; de março a setembro do ano do vencimento, utilizando o contrato futuro com vencimento em outubro; de maio a novembro, utilizando o contrato futuro com vencimento em dezembro.

Da mesma forma, os melhores momentos para a estratégia de hedge de compra são: de outubro do ano anterior a abril do ano do vencimento, utilizando o contrato futuro com vencimento em maio; e de dezembro do ano anterior a junho do ano do vencimento, utilizando o contrato futuro com vencimento em julho.

Os contratos futuros com vencimento em dezembro apresentam os maiores riscos de base. A região que tem o maior risco de base para esse vencimento é Goiânia, e a que tem o menor é o Noroeste do Paraná. Já os contratos que possuem os menores riscos de 
base são os com vencimento em julho, sendo o Triângulo Mineiro o maior risco de base, e Cuiabá o menor para esse vencimento. Nota-se, ainda, que o fortalecimento da base não é diretamente proporcional ao risco de base, predominando casos em que maior rentabilidade é acompanhada por menor risco e vice-versa.

Em termos de recomendações, ressalta-se que os resultados aqui encontrados se baseiam na média do que ocorreu no passado. Dessa forma, devem ser usados mais como indicações para planejamento do que como regra de decisão, uma vez que, diante de mudanças conjunturais, os hedgers devem rever, continuamente, suas estratégias. Por exemplo, se num determinado momento, após a implantação de uma estratégia de hedge, um hedger estiver convicto de que os preços se moverão num sentido que lhe proporcione perdas contínuas no mercado futuro, seria interessante que ele encerrasse sua posição, evitando o desembolso de ajustes diários, mesmo que o comportamento da base no passado sugerisse a manutenção da estratégia.

Como limitação deste estudo, tem-se o reduzido tamanho das séries obtidas, sendo que uma série maior poderia dar mais confiança nas generalizações dos resultados. Dessa forma, sugere-se, para próximos estudos, a análise de uma série mais extensa e também o cálculo da base e do risco de base para outras regiões do Brasil.

\section{Referências}

BARROS, Á. de M.; AGUIAR, D. R. D. Gestão do risco de preço de café arábica: uma análise por meio do comportamento da base. Rev. Econ. Sociol. Rural, v.43, n.3, p.443-464, jul./sep. 2005.

BARROS, G. S. et al. Elaboração de indicadores de preços de soja: um estudo preliminar. Piracicaba: FEALQ/ESALQ, 1997.

BARROS, G. S. C. et al. Mercados futuros e política agrícola no Brasil. Piracicaba: ESALQ, Departamento de Economia, Administração e Sociologia, 2000.

BM\&F. Bolsa de Mercadorias \& Futuros.

Disponível em: <http://www.bmf.com.br>. Acesso em: 05 jul. 2006.

CASTRO JÚNIOR, L. G. de. Impactos da liquidação financeira sobre a eficiência de hedging nos contratos futuros das commodities boi gordo e soja. 1999. $153 \mathrm{f}$. Tese (Doutorado em Economia) - Escola Superior de Agricultura "Luiz de Queiroz", Universidade de São Paulo, Piracicaba, 1999.
CEPEA. Centro de Estudos Avançados em Economia Aplicada. Disponível em: <http:// www.cepea.esalq.usp.br $>$. Acesso em: 15 jun. 2006.

FILENI, D. H. O risco de base, a efetividade do hedging e um modelo para a estimativa da base: uma contribuição ao agronegócio do café em Minas Gerais. 1999. 137 f. Dissertação (Mestrado em Administração) - Universidade Federal de Lavras, 1999.

IPEA. Instituto de Pesquisa Econômica

Aplicada. Disponível em: < http://www.ipeadata. gov.br >. Acesso em: 15 jun. 2006.

SIMON, Y. Les marchés dérivés: origine et développement. Paris: Economica, 1994.

ROCHELLE, T. C. P. O contrato futuro de boi gordo: uma análise do impacto da introdução financeira sobre o risco de base. 1997. 140f. Dissertação (Mestrado em Economia) - Escola Superior de Agricultura "Luiz de Queiroz" Universidade de São Paulo, Piracicaba, 1999. 
SHARPE, W. F.; GORDON, J. A.; BAILEY, J. V.

Investments. 5. ed. Princenton: Prentice Hall, 1995.

SILVEIRA, R. L. F. da. Análise das operações

de cross hedge do bezerro e do hedge do boi

gordo no mercado futuro da BM\&F. 2002. 122

f. Dissertação (Mestrado em Economia) - Escola

Superior de Agricultura "Luiz de Queiroz"-

Universidade de São Paulo, Piracicaba, 2002.

TEIXEIRA, M. A. Mercados futuros:

fundamentos e características operacionais. São

Paulo: Bolsa de Mercadorias \& Futuros, 1992. 